
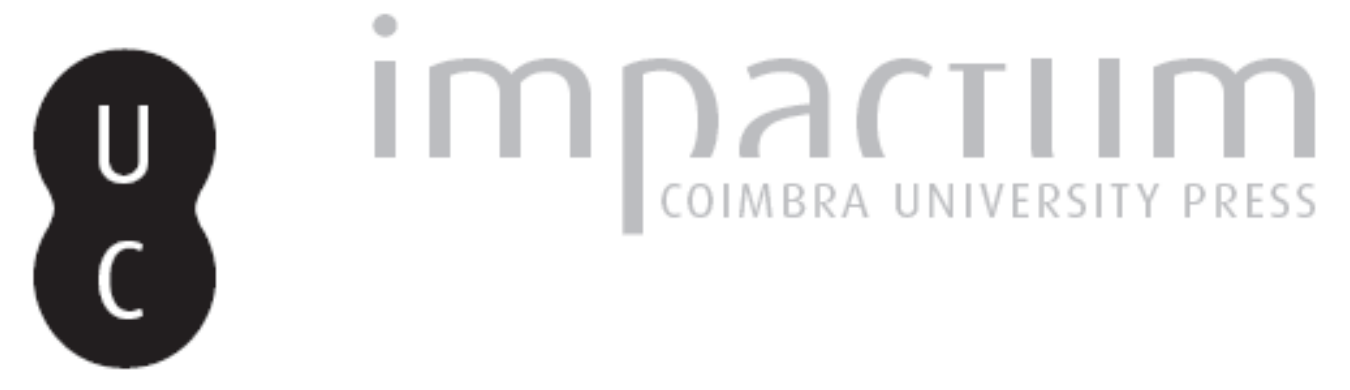

\title{
A crise ambiental na sociedade de risco
}

\section{Autor(es): Guerra, Sidney}

Publicado por: Universidade Católica de Petrópolis

URL persistente:

URl:http://hdl.handle.net/10316.2/33889

DOI:

DOI:http://dx.doi.org/10.14195/2175-0947_1-2_8

Accessed : $\quad$ 26-Apr-2023 15:07:12

A navegação consulta e descarregamento dos títulos inseridos nas Bibliotecas Digitais UC Digitalis, UC Pombalina e UC Impactum, pressupõem a aceitação plena e sem reservas dos Termos e Condições de Uso destas Bibliotecas Digitais, disponíveis em https://digitalis.uc.pt/pt-pt/termos.

Conforme exposto nos referidos Termos e Condições de Uso, o descarregamento de títulos de acesso restrito requer uma licença válida de autorização devendo o utilizador aceder ao(s) documento(s) a partir de um endereço de IP da instituição detentora da supramencionada licença.

Ao utilizador é apenas permitido o descarregamento para uso pessoal, pelo que o emprego do(s) título(s) descarregado(s) para outro fim, designadamente comercial, carece de autorização do respetivo autor ou editor da obra.

Na medida em que todas as obras da UC Digitalis se encontram protegidas pelo Código do Direito de Autor e Direitos Conexos e demais legislação aplicável, toda a cópia, parcial ou total, deste documento, nos casos em que é legalmente admitida, deverá conter ou fazer-se acompanhar por este aviso.

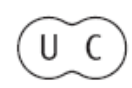



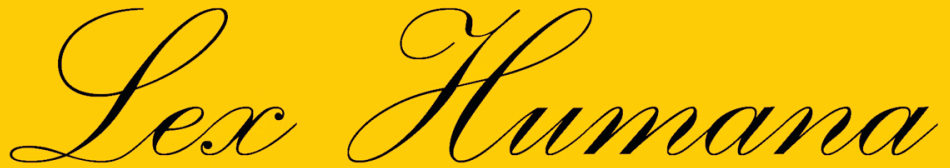

Revista do Programa de Pós-Graduação em Direito da UCP

ISSN(e) 2175-0947

Universidade Católica de Petrópolis Rua Benjamin Constant, 213 - Petrópolis - Centro CEP 25610-130

Tel: (24) 2244-4000 E-mail: lexhumana@ucp.br 


\section{A Crise Ambiental na Sociedade de Risco}

Sidney Guerra ${ }^{1}$

Resumo: Uma das questões mais alarmantes atualmente é a crise ambiental que ocorre em nosso planeta. A sociedade global, apesar dos sinais de crise evidenciados, continua a explorar de forma predatória os recursos naturais visando o crescimento econômico. A suportabilidade natural da Terra está sendo ultrapassada gerando riscos que afetam a vida e a qualidade de vida dos seres humanos. Infelizmente falar em crise num mundo que há muito tempo perdeu a capacidade de causar alarme parecem não despertar maiores interesses para que medidas efetivas sejam realmente tomadas. Urge a mobilização da sociedade para reverter o quadro de destruição em massa do planeta.

Palavras Chave: Meio Ambiente. Crise Ambiental. Sociedade de Risco

Resumo: Uno de los problemas más alarmantes na actualidad es la crisis ambiental que se produce en nuestro planeta. La sociedad global, a pesar de los signos de crisis sigue funcionando en un ritmo depredador de los recursos naturales en razon del crecimiento económico. La suportabilidad natural de la Tierra supera la tolerancia de los recursos naturales y generan riesgos que afectan la vida y la calidad de vida de los seres humanos.

Lamentablemente hablar de crisis en un mundo que hace tiempo perdió la capacidad de causar alarma no parece despertar más interés que la eficacia de las medidas tomadas son en realidad. Instan a la movilización de la sociedad para revertir el marco de destrucción en masa en el planeta.

Palabras clave: Medio Ambiente. Crisis ambiental. Sociedad de riesgo

1 Pós-Doutor pelo Centro de Estudos Sociais da Universidade de Coimbra; Pós-Doutor pelo Programa Avançado em Cultura Contemporânea da Universidade Federal do Rio de Janeiro (UFRJ), Doutor e Mestre em Direito. Professor da Universidade Federal do Rio de Janeiro e da Universidade Católica de Petrópolis. Contato: sidneyguerra@terra.com.br 


\section{Introdução}

Até poucos anos atrás o estudo do ambiente não recebia muita atenção. Todavia, esse cenário se alterou e essa mudança decorre, especialmente, dos graves sinais da crise ecológica que se apresentam para a humanidade. Para compreender a mudança de paradigma, necessário que sejam levados em consideração dois processos concomitantes e interligados: o desenvolvimento de uma consciência ambiental globalmente difundida e a necessidade premente de formulação de políticas públicas de proteção ao ambiente.

No mesmo ritmo em que a preocupação com questões ambientais se tornou prioridade para setores sociais cada dia mais amplos, o ativismo verde deixou o campo exclusivo das organizações não governamentais e ingressou no debate político e econômico.

Nesse sentido é que são apresentados os novos paradigmas da ecologia política que procura aproximar cada vez mais a problemática para todos os segmentos da sociedade. São eles:

a) a ecologia, cultura global, diz respeito ao conjunto das atividades humanas, à questão da relação entre o homem e a natureza, bem como aos assuntos da cidadania. Uma vez que o projeto de domínio e de posse da natureza é, ao mesmo tempo, um projeto de controle do homem e da sociedade, a ecologia não poderá ser identificada, sob a forma de "problema do ambiente", com uma nova dimensão da política, da ciência, da técnica, da economia e da cultura. Ela deve, pelo contrário, permitir repensar estes diferentes domínios da imaginação e da ação humanas, tanto nos seus fundamentos teóricos como nas suas aplicações concretas;

b) os impasses da civilização atual baseiam-se, em última instância, no dogma ocidental da expansão ilimitada dos desejos e das necessidades. Sem procurar regressar a um estado "primitivo" 
ou "selvagem", tornou-se necessário redefinir estes desejos e necessidades e ter em conta, conscientemente e voluntariamente, as suas limitações. Em vez de se fazer mais com mais, ou mais com menos, é preciso tentar fazer-se diferente e melhor com menos;

c) este novo paradigma supõe uma alteração radical dos valores, tanto no nível individual como no coletivo. Noções como as de economia, serviço, oferta, gratuidade e equidade devem tornar-se os principais impulsionadores da ação individual. O crescimento pelo crescimento, as técnicas de manipulação de massa, o avanço da ciência e da técnica, a situação laboral generalizada geram necessidades artificiais e devem ser postos em causa ou abandonados. No domínio crucial do trabalho, é necessário promover não uma libertação do trabalho, quer liberte, ao mesmo tempo, da necessidade frenética de consumir; d) esta revolução nos valores assenta, ela própria, numa renovação das formas de vida microssociais e comunitárias. Rompendo com o desenraizamento que conduz à centralização e a uniformização, a sociedade ecológica edifica-se sobre um conjunto de grupos restritos, de dimensões variáveis segundo os lugares e os casos, mas sempre à medida do homem, e que possibilitam o respeito e o desenvolvimento de culturas e identidades diversas;

e) esta renovação das microsociedades deve encontrar o seu correspondente no plano político. Uma maior autonomia das coletividades territoriais, reais poderes de decisão ao nível da sociedade, formas mais diretas de democracia, devem permitir substancializar a democracia representativa. ${ }^{2}$

De fato, a preocupação ambiental se espraia no mundo exigindo maior participação e engajamento de todos na busca de instrumentos para ecológico. Lisboa: Instituto Piaget, 1991, p. 90 
impedir ou diminuir a degradação ambiental e os conseqüentes problemas que emergem no âmago da sociedade de risco.

Infelizmente, apesar da mobilização dos vários atores sociais, os resultados ainda não podem ser comemorados, na medida em que ficam evidentes sérios prejuízos relacionados à destruição da natureza, do patrimônio ambiental, dos bens paisagísticos etc.

Leite e Ayala advertem que a crise ecológica permite evidenciar que nas sociedades contemporâneas observa-se a emergência de novas feições de racionalidade social reveladas pela forma distinta pela qual o risco é assimilado e interpretado nessas sociedades. Esse dado diferencia essencialmente tais riscos e os relaciona intimamente aos novos problemas ambientais:

As sociedades contemporâneas protagonizam o cenário de uma segunda revolução na dinâmica social e política, que se desenvolve no interior de um complexo processo de globalização de conteúdo plural, que marca o desenvolvimento de uma sociedade global do risco.

$\mathrm{O}$ atributo que diferencia a sociedade mundial do risco é a necessidade de concretização de uma variada relação de objetivos ecológicos, econômicos, financeiros, sociais, políticos e culturais, que são contextualizados de forma transnacional e sob a abordagem de um modelo político de governança global, de gestão de novas ameaças comunitárias. ${ }^{3}$

Com efeito, a crise ecológica passou a ser reconhecida a partir do momento em que a degradação ambiental atingiu índices alarmantes e tomouse consciência de que a preservação de um ambiente sadio está intimamente ligada a preservação da própria espécie humana.

Matérias relativas ao efeito estufa, destruição da camada de ozônio, redução da biodiversidade, poluição do solo, da água e do ar, tratamento

3 LEITE, Jose Rubens Morato; AYALA, Patrick de Araújo. Direito ambiental na sociedade de risco. Rio de Janeiro: Forense Universitária, 2004, p. 26-27 
inadequado do lixo já não estampam apenas as páginas catastróficas de autores de ficção científica, mas as páginas dos jornais e as agendas de qualquer governo.

A crise ecológica não é uma mera disputa política ou ideológica. O debate ambiental também está perpassado por disputas científicas. Diferentemente dos anos 60, em que uma parte expressiva dos cientistas desconfiava da existência da crise ecológica, hoje a ciência não apenas a admite como também vem empenhando-se em atendê-la, apontando suas causas, características, profundidades e conseqüências. $\mathrm{O}$ envolvimento dos cientistas nesse debate e o gradativo surgimento das ciências ambientais vêm contribuindo para revelar a crise ecológica nos seus diferentes ângulos. Em virtude disso, ignorar a crise ficou difícil, podendo o preço de subestimála ser elevado demais. ${ }^{4}$ Assim sendo, o presente estudo apresentará alguns pontos relativos a crise ambiental na sociedade de risco.

\section{A crise ecológica}

O marco teórico para a utilização predatória dos recursos ambientais remonta à revolução industrial, tendo como palco a Inglaterra do século XVIII. A Revolução Industrial encerrou a transição entre feudalismo e capitalismo, e, portanto, a fase de acumulação primitiva de capitais e de preponderância do capital mercantil sobre a produção.

Houve a substituição das ferramentas pelas máquinas, da energia humana pela energia motriz e do modo de produção doméstico pelo sistema fabril. A revolução industrial produziu um enorme impacto sobre a estrutura da sociedade, num processo de transformação acompanhado por notável evolução tecnológica.

Inicia-se um período da história onde prevalece o consumo

4 TREVISAL, Joviles Vitório. A educação ambiental em uma sociedade de risco. Joaçaba: Ed. Unoesc, 2003, p. 22 
desenfreado, especialmente nos países desenvolvidos que para atender a demanda do mercado precisa de matérias-primas produzindo exploração descontrolada dos recursos naturais existentes no planeta. Entretanto, a busca dessas matérias-primas não ficou limitada aos países desenvolvidos, ao contrário, ela passou a ocorrer no plano global e de maneira predatória para atender aos anseios da sociedade ávida pelo consumo.

Carneiro $^{5}$ ao apresentar as origens da crise ambiental demonstra o problema partindo de duas esferas concêntricas, onde a maior representa o sistema ecológico e a menor o sistema econômico. Assevera que a situação permaneceu até fins do século XIX, ocasião em que a demanda das matérias primas, energia e o nível de geração de resíduos por parte das atividades econômicas produtivas, não comprometia a dinâmica dos ambientes naturais. Todavia, no século $\mathrm{XX}^{6} \mathrm{o}$ sistema econômico cresceu de maneira significativa propiciando uma grande mudança no sistema ecológico, acarretando assim exaurimento dos recursos naturais e incapacidade dos ecossistemas de absorverem as agressões impostas pela expansão econômica.

A partir daí evidencia-se o surgimento da crise ambiental que na atualidade demonstra claramente sinais de que estamos ultrapassando os limites de suportabilidade natural do planeta trazendo sérios prejuízos no

5 CARNEIRO, Ricardo. Direito ambiental: uma abordagem econômica. Rio de Janeiro: Forense, 2003, p. 36-37

6 LEITE e AYALA, op. cit., p. 11, advertem que a veiculação de novos processos e técnicas de produção, associados à modificação das relações de apropriação econômica dos bens de produção e a terceirização dos processos de gestão e legitimação do conhecimento que caracterizaram um novo perfil do capitalismo e o desenvolvimento das sociedades industriais do século XX são referenciais que provocaram profundas transformações não apenas sobre a forma de organização das relações econômicas e sociais, mas sobretudo sobre o modo como seriam, a partir desse momento, definidas e legitimadas as relações de poder, bem como as condições de seu exercício, de acordo com novas qualidades de conflitos até então desconhecidas das instituições, exigindo, por sua vez, formas diferenciadas de atuação institucional,conjugadas com a especificação de novos objetivos políticos por parte dos Estados. 
campo econômico, político, social e, por óbvio, para a existência da vida, produzindo um grande temor para a sociedade em termos planetários.

Observa-se também que além dos recursos ambientais terem sido utilizados de maneira indevida, a maior parte dos benefícios decorrentes desta exploração predatória foi drenada para garantir a afluência econômica e os elevados padrões de consumo dos chamados países centrais, restando grandes contingentes da população mundial em situação de avassaladora miséria e penúria social. ${ }^{7}$

A partir do quadro negativo que se desenhou desde então, a expressão que se apresenta com larga incidência quando se discute o ambiente, no século XXI, é medo. Como acentuam Alfhandéry, Bitoun e Dupont não um medo surdo, mudo, e que teria vergonha de si próprio, mas um medo ostensivo, que se diz e escreve, que se publica e filma, que se oferece num espetáculo à medida da mundialização da comunicação. O medo ecológico é um grande medo que envolve o planeta. ${ }^{8}$

É indubitável que esse grande medo ecológico esteja intimamente ligado aos sinais de crise ambiental que além de serem amplamente noticiadas pelos diversos meios de comunicação social, podem ser hoje enxergados e sentidos.

Para que possa ser medido até que ponto o medo ecológico está ligado ao caráter inédito e singular da condição do homem moderno, basta verificar os três grandes temas que dominam o movimento ecológico internacional: o esgotamento dos recursos naturais, a multiplicação dos detritos industriais e a destruição das culturas tradicionais, como se vê:

A idéia de um possível esgotamento dos recursos naturais constituiu nos inícios dos anos setenta, com o relatório Meadows, uma das primeiras manifestações de uma consciência ecológica mundial. Pela primeira vez, uma civilização poderia, à escala 
planetária, dilapidar os recursos do solo e do subsolo, isto é, a herança geológica humana e na hipótese mais pessimista, caminhar rapidamente para um desastre, ou, na mais otimista, legar às gerações futuras problemas energéticos e alimentares insolúveis. A questão dos resíduos industriais, e, em particular, sobre os resíduos nucleares, nos coloca desde já face aos problemas sem precedente de recuperação, de armazenamento e de tratamento que ameaçam quotidianamente a nossa segurança, mas determinam também a nossa relação com o futuro, com o espaço e com o tempo que hão de vir. (...) Assim, a idéia de que nós possamos deixar às gerações futuras um mundo onde será impossível viver, pejado de zonas interditas de riscos perfeitamente incomensuráveis, já não é uma visão do espírito mas uma das conseqüências prováveis do desenvolvimento da ciência contemporânea e, por conseguinte, uma dimensão maior da condição do homem moderno. ${ }^{9}$

Finalizando a idéia acima apresentada, no que tange aos três grandes temas que dominam o movimento ecológico no plano internacional, os autores chamam atenção para uma dimensão diferente mas não menos essencial que é a destruição das culturas tradicionais e mencionam a "angústia de ter, ao destruir o outro, posto em perigo o futuro de todos. A de se estar condenando, ao anular a diversidade da espécie humana, a uma solidão eterna e inquieta." 10

Diante das incertezas e do medo, o que podemos fazer? Apenas nos conformar com ele (medo) e com os sérios problemas que emergem no plano global em matéria ambiental? Claro que não.

Caminhos alternativos têm sido propostos. Se fossem levados em consideração os posicionamentos dos ecologistas, para compatibilizar as aspirações materiais da humanidade com a preservação dos ecossistemas naturais e a manutenção dos padrões mínimos de qualidade de vida, estes iriam

Idem, p. 73

Ib idem, p. 74 
propugnar pela diminuição dos atuais níveis de crescimento econômico; para refrear o aumento populacional; para demover as pessoas de seus hábitos de consumo; alterar radicalmente as matrizes energéticas fósseis, substituindoas pelo fluxo permanente da energia solar; investir maciçamente os recursos hoje disponíveis na recuperação de ambientes degradados e no combate à pobreza e, sobretudo, mudar radicalmente os valores socialmente aceitos, eliminando o individualismo em favor da simplicidade e da austeridade.

Destarte, a perspectiva que parece viável (no plano econômico, ecológico e social) concentra-se na busca do direcionamento da racionalidade econômica para a obtenção de soluções baseadas em incentivos que encorajem os comportamentos ambientalmente sensatos. ${ }^{11}$

Também numa tentativa de minimizar esses efeitos nefastos ao meio ambiente, sob pena de comprometer a vida em nosso planeta, têm-se desenvolvido uma consciência ecológica para frear esses abusos, envolvendo os diversos atores (Estados, Organizações Internacionais, Organizações Não Governamentais, indivíduo). Ainda assim, tem sido evidenciados grandes sinais de crise ${ }^{12}$ em relação ao ambiente.

\section{Desertificação e perda da biodiversidade}

A perda de solos férteis e seu processo mais avançado denominado desertificação, têm produzido uma série de problemas em todo o planeta que vão desde a extinção de espécies da fauna e da flora até a inviabilidade de qualquer tipo de atividade econômica e, a conseqüente migração de pessoas (seja no plano interno, seja no plano internacional).

Isso porque com a desertificação ocorre a transformação de uma determinada área em um grande deserto, que é uma região que recebe pouca ou nenhuma chuva, e a grande dificuldade do desenvolvimento de qualquer

11 CARNEIRO, Ricardo, op. cit., p. 3

12 Vide GUERRA, Sidney. Direito internacional ambiental. Rio de Janeiro: Freitas Bastos, 2006. 
tipo de vida.

A perda de solos férteis apresenta índices alarmantes. A cada ano, seis milhões de hectares de terras produtivas se transformam em desertos e são destruídos mais de onze milhões de hectares de florestas. Aproximadamente $10 \%$ das terras potencialmente férteis do planeta viraram desertos ou foram aniquilados pela intervenção humana enquanto $25 \%$ estão em perigo.

A cada ano, perdem-se 8,5 mihões de hectares de florestas tropicais pelo desmatamento. Essa redução de floresta contribui para o aumento de $20 \%$ de CO2 atmosférico, enquanto o uso de combustíveis fósseis é responsável pelos $80 \%$ restantes. Ao todo, são quase 25 milhões de toneladas de gás carbônico lançados a cada ano na atmosfera decorrentes de atividades humanas. ${ }^{13}$

De acordo com o que estabelece a Convenção das Nações Unidas de Combate à Desertificação, a desertificação é definida como sendo a degradação da terra nas zonas áridas, semi-áridas e sub-húmidas secas resultantes de factores diversos tais como as variações climáticas e as atividades humanas.

Com o avançar dos problemas relativos a desertificação, várias outras expressões foram conceituadas para melhor entendimento da matéria, a saber:

"Deserto: região de clima árido; a evaporação potencial é maior que a precipitação média anual. Caracteriza-se por apresentar solos ressequidos; cobertura vegetal esparsa, presença de xerófilas e plantas temporárias;

Desertificação: origina-se pela intensa pressão exercida por atividades humanas sobre ecossistemas frágeis, cuja capacidade de regeneração é baixa;

Processo de desertificação: diz respeito a atividade predatória que irá conduzir a formação de desertos;

Área de desertificação: é a área onde o fenômeno já se manifesta;

Área propensa à desertificação: área onde a fragilidade do ecossistema favorece o processo de instalação da desertificação; 
Deserto específico: a desertificação já se manifesta em grau máximo."

A desertificação decorre do mau uso do solo e da água (ações antrópicas) como também em razão de acontecimentos naturais, tendo como causas mais freqüentes o desenvolvimento de atividades agropecuárias, mineração, irrigação mal planejada e no desmatamento indiscriminado.

O termo desertificação pode produzir a falsa impressão do problema que existe hoje no plano global. Não se trata de questões isoladas; ao contrário, existem áreas desertificadas em todos os pontos do globo (América, Ásia, Europa, África e Austrália) pelo uso predatório e irregular do solo. A desertificação ocorre em mais de 100 países do mundo sendo, portanto um problema de natureza internacional.

No Brasil, por exemplo, existem quatro áreas que são chamadas núcleos de desertificação, onde é intensa a degradação. Elas somam 18,7 mil km² e se localizam nos municípios de Gilbués, no Piauí; Seridó, no Rio Grande do Norte; Irauçuba, no Ceará e Cabrobó, em Pernambuco. As regiões áridas, semi-áridas e subúmidas secas, também chamadas de terras secas, ocupam mais de 37\% de toda a superfície do planeta, abrigando mais de 1 bilhão de pessoas, ou seja, 1/6 da população mundial, cujos indicadores são de baixo nível de renda, baixo padrão tecnológico, baixo nível de escolaridade e ingestão de proteínas abaixo dos níveis aceitáveis pela Organização Mundial de Saúde - OMS. Mas a sua evolução ocorre em cada lugar de modo específico e apresenta dinâmicas influenciadas por esses lugares. ${ }^{14}$ Assim, são observados vários problemas decorrentes da desertificação no Brasil, tais como:

1. Eliminação da cobertura vegetal original e presença de uma cobertura invasora, com conseqüente redução na biodiversidade e do patrimônio genético regional.

2. Perda parcial ou total do solo seja por fenômenos físicos (erosão) ou fenômenos químicos (salinização e alcalinização), acompanhada do aumento 
da freqüência de rodamoinhos e tempestades de areia.

3. Diminuição na quantidade e qualidade dos recursos hídricos, afetando principalmente o escoamento superficial, tanto na quantidade como no período.

4. Diminuição na fertilidade e produtividade do solo, afetando a produtividade e produção, animal e agrícola, gerando com isto, o abandono de áreas, principalmente em casos de mineração e com conseqüente aumento nas atividades extrativistas.

5. Na população humana: diminuição da densidade, aumento relativo no número de jovens e anciões, predomínio do sexo feminino em função da alta migração do sexo masculino, o que vai incrementar os cinturões de pobreza dos centros urbanos.

6. No comportamento sócio-econômico: diminuição nas fontes de ingresso e da relação produção/consumo, isto é, a ocupação humana que era basicamente primária ou produtiva, passa a ser secundária ou consumista. Aumento do desemprego, diminuição do investimento, crescente importação de produtos de consumo e, finalmente, a geração de uma consciência de abandono, provocada por atitudes de resignação frente aos graves problemas de sobrevivência e do abandono e desprezo por parte das instituições governamentais. ${ }^{15}$

Sem embargo, com a perda de solos férteis e a desertificação (sua fase mais acelerada), observa-se a produção de efeitos diversos e várias conseqüências de natureza ambiental, econômica e social. Então vejamos:

No que tange a atividade econômica, esta acaba sendo inviabilizada pela queda na produtividade e produção agrícolas, na impossibilidade de desenvolver atividades de natureza primária (agricultura e pecuária), na diminuição da renda do consumo das populações culminando, por vezes, no deslocamento de milhares de pessoas de seus respectivos lugares de origem.

Esse fenômeno de migração (nacional ou internacional) produz o 
chamado "refugiado ambiental" com os múltiplos problemas em decorrência do descolamento em massa, tais como: aumento da mortalidade infantil, a diminuição da expectativa de vida da população e a desestruturação das famílias como unidades produtivas, perda de qualidade de vida etc.

Outro ponto que não pode ser desprezado corresponde ao desaparecimento de espécies da fauna e da flora. A biodiversidade reflete o grau de espécies existentes na natureza e contemplam plantas, animais, microorganismos e seus respectivos genes, bem como os ecossistemas e processos ecológicos que eles integram.

O desaparecimento da biodiversidade chegou a um nível estarrecedor, como nas palavras de Ricardo Carneiro:

Apesar de ainda desconhecer a maior parte das formas de vida do planeta, a pessoa humana tem provocado a extinção de várias espécies em um ritmo assustador, sobretudo em função do desmatamento para a expansão da fronteira agrícola, para a produção de carvão e para exploração de madeira, aliado à prática das queimadas, ao comércio ilegal de animais e de produtos de origem faunística, como peles, marfins etc., além da contaminação de rios, lagos e oceanos. As estimativas são espantosas: entre 1500 e 1850 uma espécie era eliminada a cada dez anos; entre 1850 e 1950 uma espécie por ano foi extinta; em 1990, possivelmente desapareceram dez espécies por dia e por volta do ano 2000 uma espécie deverá desaparecer a cada hora; de 1975 a 2000 foram eliminadas da face da Terra cerca de $20 \%$ de todas as espécies vivas; desde 1950 foi perdido $1 / 5$ das florestas tropicais do mundo; a cada ano são desertificados cerca de 20 milhões de hectares de áreas florestadas. Atualmente, mais de 14\% das espécies vegetais conhecidas estão em processo de extinção; 2/3 das 9600 espécies de aves que habitam o planeta estão em declínio e $11 \%$ estão ameaçadas de extinção ; $11 \%$ das 4400 espécies de mamíferos encontram-se em perigo iminente de desaparecimento e $1 / 3$ de todas as espécies de peixes que ocupam os oceanos, lagos e rios 
está sob ameaça direta. ${ }^{16}$

\section{Quantidade e qualidade da água}

Havia no passado uma percepção de que a água era um recurso ilimitado e talvez por essa razão a utilização do referido recurso tenha ocorrido de forma indiscriminada.

A água é um bem vital para a existência da vida de todas as espécies e, em especial, para o ser humano, sendo certo afirmar que sua utilização vai para além do consumo orgânico haja vista que é utilizada em diversas outras atividades realizadas pelo ser humano, tais como: uso doméstico, indústria, agricultura etc.

No uso doméstico podem ser apontados, além do consumo para beber e higiene pessoal, a lavagem de roupas, pisos, cozimento de alimentos, irrigação de jardins e outros. Também na indústria a água é utilizada para lavar e arrefecer o maquinário manufaturador, mas é na agricultura que ocorre um grande volume de água desperdiçada.

Ao desperdiçar a água, as pessoas negam seu valor e demonstram claramente a visão míope diante dos acontecimentos presentes e futuros da humanidade, ensejando uma verdadeira mudança de comportamento sobre a utilização racional desse bem precioso. Atentem para a informação abaixo:

A falta de água e a sede são experiências desesperadoras. Um ser vivo privado de água se fragiliza e morre muito mais rapidamente que um privado de alimentos. A sede é mais fatal que a fome. Apenas três dias é o tempo de vida que resta a uma pessoa que deixa de ingerir água enquanto que sem alimento uma pessoa sobrevive até quarenta dias. Ao perdermos um litro de água sentimos sede; no segundo, sentimos fadiga e, com o sexto, começamos a correr 
risco de morte. ${ }^{17}$

Sem embargo, de toda água existente no planeta 97,5\% é salgada e apenas 2,5\% é doce sendo que esse percentual não está acessível para o consumo humano. Então vejamos: dos 2,5\% existentes de água doce, 2,493\% encontram-se nas grandes geleiras e em regiões subterrâneas de difícil acesso; $0,007 \%$ é que estão à disposição do consumo humano nos continentes, tanto em rios quanto em lagos.

Além dos problemas acima apresentados em relação à quantidade da água e má utilização do referido recurso, não se pode olvidar que a água disponível tem-se apresentado com qualidade extremamente duvidosa.

Com efeito, apesar de sua grande importância, hodiernamente a água tem sido utilizada de forma predatória ensejando uma verdadeira "crise da água", onde se observa em várias regiões do planeta pessoas que morrem por falta do referido recurso.

Especialistas afirmam que a escassez da água de qualidade para o consumo humano será o maior problema do século XXI e que irão afetar mais de dois terços da humanidade nos próximos anos:

Estudo da ONU estima que problemas de abastecimento irão afetar dois terços da humanidade por volta de 2025. O numero de pessoas vivendo nas regiões com problemas graves ou crônicos de falta de água quadruplicará nos próximos vinte e cinco anos, ou seja, um terço da população mundial estará, de alguma forma, passando sede. Nos países em desenvolvimento, apenas metade da população tem acesso a água potável de boa qualidade. Na China, 125 milhões de pessoas não tem acesso à água potável; na Índia, são cerca de $19 \%$ e na África do Sul, $30 \%$ da população total. ${ }^{18}$

A “distribuição de água” em termos planetários não ocorre de forma equânime e isso também é fator de grande estresse e preocupação no plano 
global. Para se ter a noção da gravidade dos fatos, da água doce existente e disponível no mundo, o Brasil é detentor do correspondente a quase um quinto (20\%). Essa condição propicia a cada brasileiro a disponibilidade do equivalente a 34 milhões de litros de água (em tese).

Nesse sentido, a escassez da água tornou um grave problema para a humanidade ensejando a realização de vários congressos e reuniões no plano internacional no intuito de buscar resultados favoráveis para esse sério problema.

\section{Aquecimento global, efeito estufa e chuva ácida}

O principal fenômeno relacionado ao aquecimento global é o efeito estufa, que consiste na retenção de calor pela atmosfera em razão da presença excessiva de compostos gasosos em sua estrutura.

O efeito estufa é um fenômeno natural extremamente útil e importante para que haja vida na Terra. Se não houvesse esse fenômeno a vida em nosso planeta seria praticamente impossível porque a temperatura seria de aproximadamente $30^{\circ} \mathrm{C}$ mais fria.

Ao chegar à Terra, parte da energia do sol é aprisionada na atmosfera e isso a mantém aquecida, a uma temperatura média de $30^{\circ}$ Celsius. É esse efeito benéfico que os cientistas chamam de efeito estufa e sem ele não haveria vida na Terra nem nos oceanos, pelos menos com a riqueza e diversidade que temos hodiernamente. O grande problema é que, nas últimas décadas, os climatologistas constataram que a temperatura média do planeta estava aumentando, ou seja, está acontecendo uma intensificação do efeito estufa. Esta intensificação é que é o problema de fato.

$\mathrm{O}$ aquecimento global pode trazer sérias conseqüências para a humanidade nos anos vindouros e de várias formas, como por exemplo, o degelo das grandes calotas polares que ao serem transformadas ao estado líquido, produzirão o aumento do volume das águas e, como conseqüência, a 
possibilidade de inundar muitas áreas do planeta.

Tal fato é aumentado especialmente a partir da revolução industrial haja vista que a emissão de gases começa a ocorrer de forma desbalanceada, o que inicia o aparecimento desse sério problema para a humanidade.

Além da industrialização, que estimula muito o aumento de gases de efeito estufa na atmosfera, como o gás carbônico em virtude da queima de combustível fóssil, apresenta-se, igualmente como grandes problemas, as queimadas das florestas e a poluição provocada pelo excesso de veículos nas cidades muito populosas que faz com que o $\mathrm{CO} 2$ se acumule no ar, absorvendo mais calor. Nesse sentido, o magistério de Carneiro:

A atividade econômica humana tem mudado substancialmente a forma pela qual a energia solar interage com a atmosfera e escapa de suas estruturas de retenção de calor. Quando os processos industriais queimam carvão, petróleo e gás natural são liberados enormes contingentes de dióxido de carbono no ar. Quando as florestas são queimadas, o carbono armazenado e aprisionado nas árvores escapa para a atmosfera. Algumas outras atividades básicas, como a criação de gado e o cultivo de arroz, emitem metano, óxido nitroso e outros gases do efeito estufa. Aumentando a capacidade da atmosfera de reter o calor refletido na superfície, as emissões de gases de efeito estufa estão perturbando a forma pela qual o clima mantém o equilíbrio entre a energia que entra e a energia que sai do planeta. Nosso modelo industrial, baseado na utilização intensiva de combustíveis fósseis, e nossas necessidades alimentares crescentes estão, na verdade, engrossando o cobertor que recobre a Terra. Se antes o clima mudava o comportamento dos seres humanos, gerando fenômenos adaptativos ou migratórios, agora são os seres humanos que estão alterando as condições climáticas. ${ }^{19}$

A concentração excessiva dos gases causadores do efeito estufa 
gera o aumento da temperatura terrestre fazendo com que o problema acima indicado ganhe contornos universalistas "globalizando" o problema, no sentido de que todos serão afetados pelos efeitos nocivos que são produzidos pelo mesmo.

Outro grave problema decorrente da queima de carvão, de combustíveis fósseis e dos poluentes industriais, é o lançamento do dióxido de enxofre e de nitrogênio na atmosfera. A combinação desses com o hidrogênio presente na atmosfera sob a forma de vapor de água apresentam como resultado as chuvas ácidas.

Chuva ácida é o termo utilizado para indicar que as águas da chuva, neve e neblina, ficam carregadas de ácido sulfúrico ou ácido nítrico e ao caírem na superfície, alteram a composição química do solo e das águas atingindo cadeias alimentares, destruindo florestas e plantações etc.

A ocorrência em larga escala da denominada chuva ácida tem-se manifestado especialmente na China, na Europa Ocidental e na Rússia, mas não se pode olvidar das áreas sob a influência de correntes de ar provenientes desses países.

Sem embargo, as idéias acima apresentadas demonstram claramente que hodiernamente vivemos, infelizmente, numa sociedade de risco que assume contornos globais.

\section{Sociedade de risco}

Ulrick Beck, em interessante ensaio sobre a reinvenção da política, afirma que a modernização reflexiva significa a possibilidade de uma (auto) destruição criativa para toda uma era, que correspondeu à da sociedade industrial e enfatiza que o "sujeito" dessa destruição criativa não é a revolução em si, tampouco a crise, mas sim, a vitória da modernização ocidental:

A burguesia não pode existir sem continuamente revolucionar os instrumentos de produção, ou seja, as relações de produção, 
e, portanto, todos os relacionamentos sociais. A manutenção inalterada do antigo modo de produção, ao contrário, era a condição primária para a existência de todas as classes industriais anteriores. A revolução constante da produção a perturbação ininterrupta de todas as relações sociais, a incerteza e agitação permanentes distinguem a era burguesa de todas as anteriores. Todos os relacionamentos estabelecidos e fixados, com sua série de idéias e pontos de vista veneráveis, estão sendo destruídos; todos os novos tornam-se obsoletos antes de poderem se fixar. Tudo que é sólido dissolve-se no ar, tudo que é sagrado é profanado e as pessoas são finalmente obrigadas a enfrentar com racionalidade as condições reais de suas vidas e de suas relações com seus semelhantes. ${ }^{20}$ (grifei)

Enfatiza que a sociedade moderna, em virtude de seu dinamismo, está acabando com suas formações de classe, camadas sociais, ocupação, papéis dos sexos, família nucelar, agricultura, setores empresariais e com os pré-requisitos e formas contínuas do progresso técnico-econômico, fazendo com que esse estágio de transformação e progresso se apresente como um tipo de modernização que destrói e que modifica as diversas formas sociais, denominada modernização reflexiva. ${ }^{21}$

A modernização reflexiva continua o autor ${ }^{22}$, implica numa grande transformação da sociedade industrial, ocorrida de maneira sub-reptícia e sem planejamento no início de uma modernização normal, autônoma e com uma ordem política e econômica inalterada, fazendo com que sejam abertos novos caminhos para a modernidade. Afirma ainda que o indivíduo que conceba a modernização como um processo de inovação autônoma deve contar, de um lado, com a obsolescência da sociedade industrial e de outro,

Idem, p. 12

$21 \quad$ Ib Idem

Ib idem, p. 13 
com a emergência da sociedade de risco.

Nas sociedades modernas de risco o investimento nas diversas alternativas de produção passa a ser por si mesmo estimulado, o consumo gera um interesse por si próprio, as sociedades capitalistas não se impõem mais limites externos, gerando decisões políticas e éticas a partir de simulações, que calculam riscos toleráveis de consumo. O indivíduo, ao mesmo tempo em que é incessantemente provocado a consumir é, também, alertado para os perigos provenientes dos excessos que a sua busca por prazer pode lhe trazer no futuro. As decisões, por estarem sob o constante alerta dos riscos, não podem, quando tomadas no presente, eliminar possíveis escolhas no futuro. Oliveira $^{23}$, afirma que é sob essa consentida esfera de imprevisibilidade das inovações e da sua continuada autodestruição, que as subjetividades são formadas sob a marca da vulnerabilidade, ao mesmo tempo em que são exigidas a se comprometerem a ser o que são pelas suas próprias escolhas diante das incertezas. Talvez, seja essa nova combinação, entre inovação e preservação, que estremece os tradicionais controles institucionais, o estado e a família, e os seus correspondentes controles morais, a educação e o direito, deixando se manifestar nessas brechas uma pluralidade de possibilidades.

A vulnerabilidade é a chave para compreensão dos riscos de forma integrada, contextualizada e que irá permitir a discussão de seus vários aspectos e que são pertinentes à ética, política e técnicas que irão conformar a distribuição dos riscos na sociedade.

Assim, por sociedade de risco entende-se uma fase do desenvolvimento da sociedade moderna onde os riscos sociais, políticos, ecológicos e individuais criados por ocasião do momento de inovação tecnológica escapam das instituições de controle e proteção da sociedade

23 OLIVEIRA, Joaquim Humberto de (GUERRA, Sidney, coord.). Direitos humanos: uma abordagem interdisciplinar. Vol. III. Rio de Janeiro: Freitas Bastos, 2007, p. 159 
industrial $^{24}$.

A sociedade de risco apresenta como característica a geração inevitável de riscos que não podem ser controlados e/ou conhecidos de maneira satisfatória a partir de processos decisórios. Beck assinala cinco grandes aspectos para se discutir a sociedade de risco, a saber:

a) Os riscos produzidos escapam à percepção sensorial direta. Permanecem invisíveis até seu conhecimento pela sociedade ou que fujam ao controle. Os riscos passam a ser socialmente construídos, modificados, dramatizados ou minimizados de acordo com o conhecimento, elevando-se a importância da mídia de massa e das profissões legais e científicas responsáveis pela definição dos riscos;

b) os riscos não respeitam necessariamente as desigualdades sociais da modernidade simples, isto é, classes, gênero, etnias, e em determinado momento atingem aqueles que os fabricaram ou os que lucram com sua ocorrência;

c) os riscos não quebram a lógica do mercado, ao contrário, surgem mercados especializados no gerenciamento e na mitigação dos riscos;

d) os conhecimentos sobre os riscos e as catástrofes ambientais ganham contornos políticos;

e) as catástrofes e os riscos socialmente reconhecidos ganham força política. $^{25}$

Vale acentuar ainda duas fases no estudo da sociedade de risco: a que corresponde a um estágio em que os efeitos e as auto-ameaças são sistematicamente produzidas, mas que não se tornam questões públicas ou o centro de conflitos políticos (sociedade de risco residual); a que surge quando

BECK, Ulrich. La sociedade del riesgo. Madri: Paidós, 1998, p. 84, BECK, Ulrich, op. cit., p. 22-24 
os perigos da sociedade industrial começam a dominar os debates e conflitos públicos, sejam eles públicos, sejam privados. Nesse caso, as instituições irão se tornar os grandes causadores das ameaças que não conseguem controlar. ${ }^{26}$

É indubitável que o risco se apresenta como construção da própria sociedade, acelerado pelo ritmo da globalização, que produz sérios desdobramentos em matéria ambiental. Nesse sentido, o magistério de Trevisal:

A problemática ambiental revela a crise da própria sociedade industrial e coloca o projeto da modernidade numa grande encruzilhada. A crise ambiental anuncia a nossa entrada numa era em que os riscos perderam sua antiga delimitação espacial, temporal e social. Os riscos agora estão em toda parte; eles se globalizaram, globalizam-nos e fazem-nos pertencer a uma 'sociedade de risco global'. ${ }^{27}$

A Revolução Industrial e a conseqüente expansão do capitalismo, ampliou de forma significativa os riscos fazendo com que deixassem de ser acidentais para se tornarem parte da modernidade. Beck $^{28}$ afirma que os riscos formam um conjunto de inseguranças e ameaças introduzidas pela própria modernização e que se relacionam diretamente às forças ameaçadoras da modernização.

Embora a Revolução Industrial tenha inaugurado esse novo momento do risco, não se pode olvidar que mudanças espetaculares aconteceram no século XX onde o mundo teve a oportunidade de assistir vários episódios que sequer poderiam ser imaginados em um passado recente.

Acontecimentos que serviram para marcar uma época de grandes transformações em todas as áreas (política, tecnologia, economia, social,

BECK, Ulrich, op. cit., p.16

TREVISAL, Joviles Vitório, op. cit., p. 65

BECK, Ulrich, op. cit., p. 21 
ambiental etc.). Nesse cenário de grandes transformações, decorrente em larga escala pelo processo de globalização, é que se evidencia também a manifestação em larga escala do risco e da própria incerteza.

A incerteza, ao lado do risco, também passou a fazer parte da época atual, tendo Giddens apresentado a seguinte contribuição:

A incerteza artificial refere-se a riscos criados pelos próprios desenvolvimentos inspirados pelo Iluminismo - nossa intromissão consciente em nossa própria história e nossas intervenções na natureza. Os riscos de grandes conseqüências com os quais nos defrontamos atualmente, e muitos outros ambientes de risco de tipo menos extensivo, são de origem social. Estamos condenados a lutar por um futuro indefinido. Em nível individual, coletivo, ou global, a acumulação de conhecimentos reflexivamente ordenado cria futuros abertos e problemáticos sobre os quais temos, por assim dizer, que trabalhar à medida que seguimos no presente. Ao fazermos isso, influenciamos os processos de mudança, mas o controle total deles foge cronicamente do nosso alcance. ${ }^{29}$

O risco está em toda parte fazendo com que prevaleça um grande sentimento de insegurança que parece ser alimentado pelo desenvolvimento das ciências e das técnicas que são cada vez melhores. O risco é a tradução de uma ameaça, de um perigo para aquele que está sujeito a ele e o percebe como tal. ${ }^{30}$

30 CALLON, Michel; LASCOUMES, Pierre; BARTHE, Yannick. Agir dans um monde incertain. Paris: Senil, 2001, p. 37: "Le risque designe un danger bien identifiqué, associé à l'occurrence d'un événement ou d'une série d'événements, parfaitement descriptibles, dont on ne sait pas s'ils se produiront mais don't on sait qu'ils sont susceptibles de se produire. Dans certains cãs, des outils statistiques appliqués à des séries d'observations systématiques appliqués à des séries d'observations systématiques faites dans lê passé permettent d'em calculer la probabilité d'occurrence, qui sera alors qualifiée d'objective. Em l'absence de telles observations, les probalités assignées dépendent des points de vue, sentiments ou convictions des acteurs: elles sont dites subjectives. Qu'elles soient subjectives ou 
Veyret o define como a percepção do perigo, da catástrofe possível e que existe apenas em relação a um indivíduo, a um grupo social ou profissional, uma comunidade, uma sociedade que o apreende por meio de representações mentais e com ele convive por meio de práticas específicas. Não há risco sem que haja um grupo que possa sofrer seus efeitos. ${ }^{31}$

O risco nasce da percepção de um perigo ou de uma ameaça potencial que pode ter origens diversas e que denomina-se álea. Esta é sentida pelos indivíduos e pode provocar prejuízos às pessoas, aos bens e à organização do território. À luz dos acontecimentos que podem desencadear uma crise, a análise dos prejuízos remete ao que se denomina de vulnerabilidade. O risco, portanto, é a representação de um perigo ou álea que afetam os alvos que

objectives, ces probabilités ont em commun de sápliquer à des évenéments connus, identifiés, dont une caractérisation précise peut être donnée, et dont ou peut expliciter les conditions de production."

31 VEYRET, Yvette. Os riscos: o homem como agressor e vítima do meio ambiente. São Paulo: Contexto, 2007, p. 11/24: Ao iniciar o estudo sobre risco a autora apresentada alguns conceitos importantes para melhor compreensão da matéria, a saber:

a) risco - é a percepção de um perigo possível, mais ou menos previsível por um grupo social ou por um indivíduo que tenha sido exposto a ele;

b) incerteza - definida como possibilidade de ocorrer um acontecimento perigoso sem que se conheça suas probabilidades;

c) indeterminação - trata-se da situação em que um acontecimento desconhecido poderia acontecer;

d) álea - acontecimento possível decorrente de um processo natural, tecnológico, social, econômico, e sua probabilidade de realização;

e) perigo - termo empregado para definir conseqüências objetivas a uma álea sobre um indivíduo, um grupo ou sobre o meio ambiente;

f) alvo - elementos ou sistemas que estão sob a ameaça de áleas de natureza variada;

g) vulnerabilidade - mede os impactos danosos sobre o acontecimento sobre os alvos afetados;

h) crise - realização concreta, material de uma álea cuja amplitude excde a capacidade de gestão espontânea da sociedade que sofre esse evento;

i) catástrofe - definida em função da amplitude das perdas causadas às pessoas e aos bens 
constituem indicadores de vulnerabilidade. ${ }^{32}$

Giddens $^{33}$ afirma que o risco se refere a infortúnios ativamente avaliados em relação a possibilidades futuras. A palavra só passa a ser amplamente utilizada em sociedades orientadas para o futuro - que vêem o futuro precisamente como um território a ser conquistado ou colonizado. $\mathrm{O}$ conceito do risco pressupõe uma sociedade que tenta ativamente romper com seu passado - de fato, a característica primordial da civilização industrial.

$\mathrm{Na}$ sociedade hodierna existem vários tipos de riscos: os riscos econômicos, geopolíticos, sociais, industriais, tecnológicos, riscos ambientais etc. Na mesma direção, Trevisal ${ }^{34}$ apresenta os vários riscos que tocam nossas vidas:

a) riscos que decorrem das crises que atingem o mercado financeiro internacional;

b) riscos ligados à saúde pública, que decorrem de epidemias de grande impacto;

c) riscos ligados à prática sexual, especialmente as doenças sexualmente transmissíveis;

d) riscos ligados a guerras e acidentes nucleares, químicos, bacteriológicos e genéticos;

e) riscos que decorrem do consumo de alimentos contaminados por bactérias e toxinas;

f) riscos decorrentes do aquecimento global e da destruição da camada de ozônio, especialmente o câncer de pele;

g) riscos provocados pela revolução genética e biotecnológica em curso;

h) riscos tecnológicos, especialmente acidentes, explosões,

Idem, p. 30 
vazamentos, incêndios;

i) riscos que decorrem da miséria, do desemprego, da subnutrição, da ausência de água potável, de esgoto, da falta de tratamento do lixo;

j) riscos sociais e afetivos, decorrentes das crises de relacionamento, interpessoais, matrimoniais, de educação dos filhos;

1) riscos ambientais.

Nesse estudo que tem por objetivo analisar a crise ecológica na sociedade de risco, deve ter destaque o ponto relativo ao risco ambiental.

\section{O risco ambiental}

$\mathrm{Na}$ sociedade global a noção de risco $^{35}$ faz com que novos questionamentos sejam produzidos nas mais diversas relações envolvendo as pessoas e o ambiente.

A crise ambiental não só é parte dessa sociedade de risco como é sua evidência e que a problemática ambiental começou a se discutida justamente a partir do momento em que a humanidade se deu conta de que a natureza havia sido dissolvida e completamente socializada. ${ }^{36}$

Como já tivemos a oportunidade de assinalar, com a "modernização reflexiva" e a globalização, que ganha impulso especialmente no século XX, traz consigo grandes mudanças para a sociedade, e por certo, para o meio ambiente.

$35 \quad \mathrm{Na}$ atual fase da modernidade, os riscos, que em outras épocas existiram como indicadores de ousadias e aventuras individuais, assumem uma dimensão globalizada. E ao atingirem tal dimensão, atingem-na não pela falta de recursos tecnológicos, mas, pelo contrário, como resultado da sua própria aplicação. 
Os riscos ambientais são resultados da associação dos riscos naturais decorrentes de processos naturais agravados pelas atividades humanas e pela ocupação do território, como por exemplo, a desertificação. Os riscos naturais são aqueles que são pressentidos, percebidos e suportados por um grupo social ou um indivíduo sujeito à ação possível de um processo físico de uma álea. ${ }^{37}$

Com efeito, a crise ambiental possibilita evidenciar que na sociedade global há formas de emergência de feições de racionalidade social reveladas pela forma distinta pela qual o risco é assimilado e interpretado fazendo com que os riscos se relacionem com os problemas ambientais, como nas palavras de Leite e Ayala:

Chernobil e a catástrofe nuclear representam ainda hoje a imagem de uma espécie de pecado original burocrático, que reconduz a onipotência das instituições de controle e o dogma da infalibilidade tecnológica (tendo a ciência como guardiã desse tabu) ao mundo terreno das falhas de segurança, da incapacidade de previsão antecipada de suas conseqüências e das limitações técnicas das instituições de controle e das instancias de decisão. O Estado deve lidar com a crise ambiental, ciente das circunstâncias diferenciadas que a caracterizam, a partir de um modelo de riscos. ${ }^{38}$

Isso porque existe uma possibilidade real da eclosão de uma guerra nuclear, de ocorrer uma calamidade ecológica, de termos uma explosão incontrolável da população, além da possibilidade de ocorrerem vários outros problemas. Em relação ao crescimento incontrolável da população, atentem para os dados em termos planetários: 1830 - 1 bilhão de pessoas; 1927 - 2 bilhões de pessoas; 1960 - 3 bilhões de pessoas; $1974-4$ bilhões de pessoas; 1987 - 5 bilhões de pessoas; 1999 - 6 bilhões de pessoas; 2007 
$-6,5$ bilhões de pessoas.

O crescimento desordenado da população mundial é fator de preocupação, principalmente pela utilização irracional dos recursos ambientais que são finitos e já se apresentam de maneira escassa. A situação se agrava ainda mais pelo próprio comportamento adotado pelas pessoas nessa sociedade competitiva, egoísta e desigual onde a grande maioria não se preocupa com o amanhã, não se preocupa com as futuras gerações e que vivem intensamente apenas o dia de hoje.

Para Beck, o risco é uma expressão que tem sua origem na modernidade e que apresenta como grande característica a organização da sociedade baseada na mudança e na ousadia, tentando tornar previsível o que é imprevisível, controlável o que é incontrolável e principalmente a criação de mecanismos que permitam a diminuição da incerteza que qualifica os efeitos da decisão, submetendo o controle do próprio futuro. Afirma ainda que o que causa a catástrofe não é um erro, mas os sistemas que transformam a humanidade do erro em forças destrutivas incompreensíveis. ${ }^{39}$

O fato é que em razão desse traço marcante da mudança e da ousadia, o mundo tem experimentado transformações significativas no ambiente. Além de tufões, tornados, furacões, avanço do volume das águas dos oceanos, podem ser sentidos outros efeitos extremamente negativos, tanto como os já indicados: o contínuo desaparecimento de espécies da fauna e da flora; a perda de solos férteis pela erosão e pela desertificação; o aquecimento da atmosfera e as mudanças climáticas; a diminuição da camada de ozônio; a chuva ácida; o acúmulo crescente de lixo e resíduos industriais; o colapso na quantidade e na qualidade da água etc.

O relatório do clima produzido recentemente demonstra bem esses efeitos desastrosos pela ação produzida pelo homem (ação antrópica) e apresenta dados preocupantes sobre as mudanças climáticas no planeta. Segundo o relatório, o cenário mundial vem sendo alterado pelas mudanças 
climáticas e a população mundial terá dificuldades para se adaptar a ele.

As mudanças incluem não só o aumento do clima em si, mas também fenômenos como precipitação e sazonalidade, importantes no que tange a capacidade de adaptação das diferentes espécies, inclusive o ser humano. Água, ecossistemas/agricultura, sociedade/economia e saúde estão entre os setores analisados pelo IPCC, indicando quais impactos os mesmos vem sofrendo e a que resultados poderemos assistir muito em breve.

Entre as previsões, o IPCC afirma que cerca de $30 \%$ de costa litorânea serão perdidos em função do aumento do nível da água, o que afetará não só a oferta de produtos (por exemplo peixes) como a própria sobrevivência das populações humanas que habitam tais áreas.

Outro dado preocupante é a mudança da distribuição geográfica de vetores. Ou seja, insetos transmissores de doenças endêmicas (malária, dengue, febre-amarela) poderão se alastrar em regiões onde não são encontrados atualmente, como na Europa e na América do Norte, já que tais regiões tendem a ficar mais quentes ao longo dos anos.

Essas alterações climáticas impactam também a produção agrícola. O IPCC prevê uma queda na produtividade de cereais em baixas altitudes e um crescimento em médias e altas altitudes.

A curto e médio prazo, os africanos é quem mais sofrerão com as conseqüências desastrosas relacionadas ao acesso à água. Entre 75 e 250 milhões de pessoas, até 2020, terão dificuldades para acessar água potável e água destinada à irrigação para agricultura.

$\mathrm{Na}$ Ásia, o derretimento do Himália provocará um aumento de enchentes, deslizamento de encostas e dificuldade de acesso aos recursos hídricos nas próximas duas ou três décadas.

$\mathrm{Na}$ Austrália (Oceania), a Grande Barreira de Corais sofrerá uma grande perda de diversidade. E, apesar do avanço da tecnologia da Austrália e Nova Zelândia, segundo o IPCC, os sistemas naturais têm limites quanto à sua adaptabilidade e o conhecimento tecnológico não será suficiente para 
reverter os danos.

$\mathrm{Na}$ América Latina, vários ecossistemas tendem a desaparecer, ou serem drasticamente reduzidos. No Brasil especialmente, a própria Amazônia, segundo os cientistas, poderá ser substituída por uma vegetação característica de cerrados (savana brasileira). Recifes de coral (estes importantíssimos para a reprodução de várias espécies marinhas) também tendem a desaparecer, já que consistem em colônias que suportam baixíssima variação climática.

Caso a demanda por recursos naturais e os índices de degradação ambiental permaneçam nas taxas atuais, é possível que, em poucos anos, os dados do relatório sejam considerados extremamente "amenos"... Aliás, isso aconteceu já na sua apresentação, quando cientistas foram acusados de suavizar os reais impactos das mudanças climáticas previstos para os próximos 50 anos. ${ }^{40}$

Não se pode olvidar que os riscos, especialmente em matéria ambiental, possuem algumas especificidades que anunciam a modernização reflexiva.

A começar pela idéia de que os riscos ambientais não estão limitados a um determinado tempo e espaço, isto é, seus efeitos podem ser sentidos com maior incidência ao longo dos anos e alcançar vários Estados-nação, fazendo com que tenhamos, de fato, um problema no plano global.

Assim, em relação a espacialidade, impende assinalar que o risco ambiental não está adstrito a um determinado espaço. Ao contrário, os efeitos que são produzidos são de natureza transnacional. Existem vários casos que podem demonstrar bem essa realidade, qual seja a da não observância das fronteiras quando da ocorrência de uma lesão ao ambiente. Evidencia-se, por exemplo, o problema da emissão dos gases poluentes, responsáveis também pelo aquecimento global. Como visto, a emissão dos gases poluentes contribuem para o denominado "efeito estufa" que produzirá efeitos em termos planetários.

Outro problema que tem sido discutido em vários foros internacionais é pertinente a poluição transfronteiriça e a produção do lixo tóxico, ou seja, 
quando ocorre o lançamento do efluente no mar ou no ar, seus efeitos não ficarão adstritos a um único Estado-nação. Muito pelo contrário, seus efeitos e desdobramentos são sentidos em Estados vizinhos e dependendo da lesão produzida, também no plano global. Do mesmo modo, o risco da eclosão de uma guerra nuclear que pode destruir a Terra em fração de poucos segundos.

No que tange a temporalidade, tal assertiva pode ser evidenciada partindo-se do caso emblemático de Chernobil, considerado o pior acidente nuclear da história. O acidente nuclear de Chernobil ocorrido no dia 26 de abril de 1986, na Usina Nuclear de Chernobil na Ucrânia - extinta União Soviética, produziu uma nuvem de radioatividade que atingiu a União Soviética, Europa Oriental, Escandinávia e Reino Unido. Grandes áreas da Ucrânia, Bielorrússia (Belarus) e Rússia foram contaminadas, resultando na evacuação e reassentamento de aproximadamente 200 mil pessoas.

Ainda hoje existem desdobramentos pelo grande acidente ocorrido na Ucrânia. Os principais países afetados (Rússia, Ucrânia e Bielorrússia) têm suportado um contínuo e substancial custo de descontaminação e cuidados de saúde devidos ao acidente de Chernobil, sendo difícil apresentar com certeza o número de mortos causados pelo acidente nuclear.

A ONU apresentou relatório no ano de 2005, atribuindo 56 mortes até aquele momento (47 trabalhadores acidentados e 9 crianças com câncer da tireóide), e estimou o número de 4000 pessoas que morrerão de doenças relacionadas com o acidente. Somado a isso, existem os casos de aborto, deformidades, doenças crônicas em razão da contaminação ambiental etc. Leite e Ayala ${ }^{41}$ sustentam ainda que:

se Chernobil pode ser considerado o marco representativo da qualidade dos riscos da segunda modernidade, invisíveis, globais e transnacionais, as sociedades contemporâneas enfrentam hoje novos desafios localizados no interior de uma segunda revolução na dinâmica social e política, que tem como marco a data de 11 de 
setembro de 2001. As sociedades contemporâneas protagonizam o cenário de uma segunda revolução na dinâmica social e política, que se desenvolve no interior de um complexo processo de globalização de conteúdo plural, que marca o desenvolvimento de uma sociedade mundial do risco.

A matéria não pode fazer parte de uma agenda despretensiosa e que esteja presente apenas em discursos políticos vazios de muitos. Ao contrário, a questão que se põe hodiernamente corresponde algo muito maior, da própria existência humana.

$\mathrm{Na}$ mesma direção, o magistério de Giddens ${ }^{42}$ que acentua que as questões ecológicas dizem respeito ao "ambiente" e que poderiam parecer que estariam compreendidas em termos da necessidade de "proteger" a terra, mas na verdade, tornou-se visível que as questões ecológicas marcam muitos outros problemas com que nos defrontamos:

Em um primeiro momento, é claro, há a questão básica da sobrevivência ou segurança global. Os "males" que nos afligem, como riscos de grandes conseqüências, têm de ser limitados ao máximo. A industrialização e o desenvolvimento tecnológico desenvolveram-se sob a égide das sociedades ocidentais. Por que as sociedades menos desenvolvidas deveriam agora embarcar em processos de industrialização em grande escala que limitam seu crescimento econômico, para ajudar a resolver problemas criados pelos ricos? A expansão da pobreza global e a demanda urgente por justiça global estão vinculadas a dilemas ecológicos. As questões ecológicas têm de ser compreendidas em termos de "fim da natureza" e da destradicionalização. ${ }^{43}$

42 GIDDENS, Anthony, op. cit., p. 224

43 Sobre o uso da expressão "destradicionalização" GIDDENS, Anthony, op. cit., p. 225, demonstra o rompimento de tradições preexistentes, e afirma que "sempre que algo usualmente determinado pela natureza, seja ela o ambiente ou a tradição, torna-se uma questão de tomada de decisão, novos espaços éticos ao abertos e novas perplexidades políticas são criadas." 
Há de se observar também que em muitos casos o risco é imprevisível e imperceptível. Imprevisível porque não há um controle do futuro, o amanhã é incerto. Por isso que Beck ${ }^{44}$ adverte que na sociedade de risco o passado perdeu seu poder de determinação do presente e as atitudes e decisões cotidianas tendem a ser motivadas por um futuro fictício, construído e incerto.

Além da imprevisibilidade, o risco, por certo, pode ser imperceptível. Novamente colhendo os ensinamentos de $\mathrm{Beck}^{45}$, na sociedade de risco a ciência tem um papel político ímpar e compete a ela (ciência) identificar os riscos, mapear as implicações e apontar as soluções. Não é possível detectar e debater as ameaças presentes na energia nuclear sem um certo grau de conhecimento científico dos processos que ela compreende.

No que tange a reflexividade, os riscos que emergem na sociedade global são, em larga escala, fabricados e refletem os comportamentos da própria sociedade.

Assim sendo, urge que haja participação mais efetiva de todos para que os problemas ambientais que se manifestam na sociedade de risco global ${ }^{46}$ não se apresentem em níveis irreversíveis. $O$ fato é que os riscos apresentados são reais e que ensejam uma tomada de consciência e de participação efetiva sob pena de comprometer a própria existência da humanidade.

Com efeito, nos estudos formulados por Beck e Giddens, há um claro entendimento que nessa "modernidade reflexiva", vários aspectos de nossas vidas serão afetados e que trarão sérias conseqüências, não só para pessoa na sua individualidade, mas também, para a sociedade como um todo.

$44 \quad$ BECK, Ulrich, op. cit., p.178

45 Idem.

46 BECK, Ulrich, op. cit., p. 19: "Na sociedade de risco, as pessoas são confrontadas com os limites e com as consequencias e suas ações, isto é, a sociedade torna-se reflexiva, o que significa dizer que ela se torna um tema e um problema para ela própria." 
A crise ambiental é um problema que hodiernamente aflige toda humanidade, entretanto apesar dos vários sinais enviados pela natureza, a sociedade continua a adotar comportamento inadequado e perigoso, que poderá trazer conseqüências nefastas para todo o planeta. Diante desse quadro negativo é que se conclama maior engajamento da sociedade civil em relação aos problemas ambientais.

\section{Considerações finais}

É indubitável que os problemas ambientais crescem e colocam em risco a existência das espécies (inclusive a humana). Muitos dos problemas que se manifestam na sociedade hodierna decorrem de comportamentos inadequados que foram desenvolvidos pelo ser humano (ação antrópica) ao longo dos anos em nome de um crescimento desenfreado.

O "progresso" não levava em consideração as limitações do ambiente e para atender aos interesses e anseios de pessoas cada vez mais ávidas pelo consumo é que se desenvolveu uma sociedade global de risco em termos ambientais.

O fato é que hoje vive-se num mundo competitivo, frenético, desigual, egoísta em que as pessoas, em geral, estão preocupadas em resolver apenas seus problemas. Afinal de contas, os compromissos assumidos são muitos. Os problemas devem ser resolvidos de maneira rápida e há uma forte pressão para que os resultados sejam velozes e positivos em todas as atividades desenvolvidas: trabalho, escola, afazeres domésticos etc.

Situações que no passado poderiam ser consideradas verdadeiras aberrações e que provocavam grande desconforto, mal-estar, tristeza e dor começam a figurar como "fatalidades" e "coisas da vida", fazendo com os comportamentos sejam considerados no mínimo como "estranhos". São deixados de lado, muitas vezes, os mais preciosos valores e a não observância de procedimentos éticos e legais em razão do momento que 
passa a humanidade.

Assim é que a morte de pessoas inocentes; as balas perdidas; a violência pela violência; o abandono de crianças em orfanatos e de idosos em asilos; a falta de sentimento e compaixão com o próximo; a indiferença com as enfermidades, guerras e catástrofes e com todos os demais problemas que afetam o planeta parecem não sensibilizar mais o comportamento do ser humano.

Vive-se um grande paradoxo: a solidão numa aldeia global. De fato, tudo que não esteja diretamente voltado ao problema ou interesse particular acaba sendo descartado ensejando a criação de uma verdadeira sociedade de risco... . Risco que se manifesta nos problemas ambientais.

Nesse diapasão, Oliveira assevera que em razão da individualização ${ }^{47}$ pela qual se atinge a política globalizada, também está presente nos problemas ecológicos. Suas conseqüências não são assuntos apenas do interesse daqueles que detém um saber especializado ou das altas cúpulas governamentais, mas reclamam a participação da parte de todo indivíduo, exigindo posturas que interfiram até mesmo no seu próprio estilo de vida ${ }^{48}$. O que provocará resistências não só dos setores menos modernizados, talvez habituados a seculares práticas degradantes do meio-ambiente, mas, com certeza, com muito mais intensidade, o que nos deixa bastante céticos, dos setores mais beneficiados pelos avanços da modernidade, que terão que abrir

$47 \quad$ BECK, Ulrick, op. cit., p. 60. “Todas as coisas consideradas perda, perigo, desperdício e decadência na estrutura esquerda-direita da política burguesa, coisas como preocupação com o eu e as perguntas: quem sou eu? o que eu quero? para onde estou indo?, em suma, todos os pecados originais do individualismo conduzem a um tipo diferente de identidade do político: a política de vida-e-morte".

48

No mesmo diapasão, BECK, Ulrich, op. cit., p. 61: “ As questões de um longínquo mundo de fórmulas químicas explodem com uma seriedade mortal nos recônditos mais internos da conduta da vida pessoal como as questões do eu, da identidade e da existência, e não podem ser ignoradas". E mais adiante, “Agora, o microcosmo da conduta da vida pessoal está inter-relacionado com o macrocosmo dos problemas globais, terrivelmente insolúveis" 
mão do exagerado consumo, conforto e lucro que são o sentido das suas vidas. ${ }^{49}$

Isso pode ser demonstrado pelo atual uso dos recursos naturais do planeta que já excedem em quase $50 \%$ a capacidade da biosfera, considerando-se o consumo de alimentos, materiais e energia. No ano de 2000, no Living Planet Report, verificou-se que se cada ser humano no planeta consumisse os recursos naturais e emitisse dióxido de carbono nos níveis dos cidadãos norte-americanos, franceses ou alemães, seriam necessários mais dois planetas terra com os recursos equivalentes ao estágio da época, de nosso planeta. ${ }^{50}$ No mesmo sentido, a contribuição de Anthony Giddens:

Enfrentar as ameaças advindas do dano aos ecossistemas da Terra provavelmente demandará respostas globais coordenadas em níveis muito distantes da ação individual. Por outro lado, essas ameaças não serão eficazmente combatidas a menos que haja uma reação e uma adaptação da parte de todo indivíduo. Mudanças generalizadas de estilo de vida, junto com uma diminuição da importância atribuída à contínua acumulação econômica, serão quase certamente necessárias se quisermos minimizar os riscos ecológicos hoje à nossa frente..$^{51}$

Infelizmente falar em crise num mundo que há muito tempo perdeu a capacidade de causar alarme, os problemas relacionados ao ambiente listados acima, devidamente comprovados por cientistas, parecem não despertar maiores interesses para que medidas efetivas sejam realmente tomadas para reverter quadro tão adverso. Urge a mobilização da sociedade para reverter o 
quadro de destruição em massa do planeta. 


\section{Referências bibliográficas}

ALFHANDÉRY, Pierre; BITOUN, Pierre; DUPONT, Yves. O equívoco ecológico. Lisboa: Instituto Piaget, 1991.

BECK, Ulrick. A reinvenção da política. Modernização reflexiva. São Paulo: UNESP, 1995.

BECK, Ulrich. La sociedade del riesgo. Madri: Paidós, 1998.

CALLON, Michel; LASCOUMES, Pierre; BARTHE, Yannick. Agir dans um monde incertain. Paris: Senil, 2001.

CARNEIRO, Ricardo. Direito ambiental: uma abordagem econômica. Rio de Janeiro: Forense, 2003.

GUERRA, Sidney. Direito internacional ambiental. Rio de Janeiro: Freitas Bastos, 2006.

GUERRA, Sidney; BUZANELLO, Jose Carlos. Direitos humanos: uma abordagem interdisciplinar. Vol. III. Rio de Janeiro: Freitas Bastos, 2007.

GIDDENS, Anthony. Para além da esquerda e da direita. São Paulo: UNESP, 1997.

GIDDENS, Anthony. As conseqüências da modernidade. São Paulo: UNESP, 1991.

LEITE, Jose Rubens Morato; AYALA, Patrick de Araújo. Direito ambiental na sociedade de risco. Rio de Janeiro: Forense Universitária, 2004. 
TREVISAL, Joviles Vitório. A educação ambiental em uma sociedade de risco. Joaçaba: Ed. Unoesc, 2003.

VEYRET, Yvette. Os riscos: o homem como agressor e vítima do meio ambiente. São Paulo: Contexto, 2007. 